Research Article

\title{
A Numerical Approach to Analyze Detail Mechanical Characteristic at the Crack Tip of SCC in Dissimilar Metal Welded Joints
}

\author{
He Xue $\mathbb{D}^{1},{ }^{1}$ Yuman Sun $\mathbb{D}^{1},{ }^{1}$ Shun Zhang $\mathbb{D}^{1},{ }^{1}$ Rehmat Bashir $\mathbb{D}^{1,2}$ Youjun Zhao, ${ }^{1}$ \\ Hongliang Yang $\mathbb{D}^{3}{ }^{3}$ Shuai Wang $\mathbb{D}^{1},{ }^{1}$ and Yongjie Yang ${ }^{1}$ \\ ${ }^{1}$ School of Mechanical Engineering, Xi'an University of Science and Technology, Xi'an 710054, China \\ ${ }^{2}$ Department of Mechanical Engineering, University of Engineering and Technology, Lahore 54890, Pakistan \\ ${ }^{3}$ Center of Engineering Training, Xi'an University of Science and Technology, Xi'an 710054, China
}

Correspondence should be addressed to He Xue; xuehe@xust.edu.cn and Yuman Sun; 19205201061@stu.xust.edu.cn

Received 12 April 2021; Revised 9 August 2021; Accepted 13 August 2021; Published 23 August 2021

Academic Editor: Paolo Ferro

Copyright ( $\odot 2021$ He Xue et al. This is an open access article distributed under the Creative Commons Attribution License, which permits unrestricted use, distribution, and reproduction in any medium, provided the original work is properly cited.

\begin{abstract}
The mechanical characteristic at the crack tip is one of the main factors affecting the stress corrosion cracking (SCC) in dissimilar metal welded joints (DMWJs). In this research, to evaluate the effect of heterogeneous material properties on the mechanical characteristic at the crack tip of DMWJs accurately, a heterogeneous material model of the SA508 Cl.3-Alloy 52M DMWJ was established based on USDFLD subroutine in ABAQUS. The comparison of the traditional "Sandwich" material model with the heterogeneous material properties, stress-strain conditions, and the plastic zone around the crack tip at the interference zone has been analyzed by the finite element method (FEM). The results indicated that the heterogeneous material model could characterize the mechanical properties of the SA508 Cl.3-Alloy 52M DMWJs accurately. In addition, the crack at the interface zone between materials will deflect along with the weld metal in two material models.
\end{abstract}

\section{Introduction}

Nickel base alloys, such as alloy $152 / 52 \mathrm{M}$, alloy $182 / 82$, and alloy 309L/308L, have been widely used as weld metals to connect the pipe nozzle and safety end of the primary circuit of the nuclear pressure vessel [1-5]. However, several studies have demonstrated that the distribution of microstructure and material mechanical properties in the heat-affected zone (HAZ) and dilution zone (DZ) of the welded joint has become much complex during the welding progress [6-11]. Meanwhile, the complicated mechanical characteristic at the crack tip caused by the heterogeneous material properties is one of the main factors for stress corrosion cracking (SCC) of dissimilar metal welded joints (DMWJs) [12]. Therefore, there is a great significance to characterize the material mechanical properties of DMWJs in detail for the safety evaluation and life prediction of the DMWJ in service environments.
Considerable research efforts have been devoted to the influence of the material constraint effect of welded joints on the mechanical characteristic at the crack tip by finite element method (FEM). Some scholars studied the mechanical characteristic at the crack tip of DMWJs based on the "Sandwich" material model, which ignores the existence of the HAZ and DZ and endows corresponding material properties to the base metal and weld metal $[13,14]$, respectively. Therefore, the traditional "Sandwich" material model can only roughly evaluate the influence of mismatch of the material mechanical properties between the base metal and weld metal on the safety of welded joints. However, the material mechanical properties of the DMWJ are not distinguished strictly at the interface zones between materials. Recent experiments in this field have obtained the material mechanical properties of the SA508 Cl.3-Alloy 52M DMWJ by microhardness test or minisized tensile test $[15,16]$. The experimental results show dramatic changes in the strength 
and work hardening exponent at the interface zones. Therefore, the mechanical characteristic at the crack tip in the interface zones of welded joints is analyzed by the traditional "Sandwich" material model, which cannot meet the requirements. In previous studies, some scholars used refined zoning of the "Sandwich" material model to improve the solution accuracy [17], but that can only realize the gradient change of material in the model, and it increases the workload. Recently, many researchers have attempted to solve this problem by using the user subroutine in ABAQUS. Chi et al. [18] complied the stress-strain curve of the unsaturated soil based on the user-defined field (USDFLD) subroutine variables at a material point in the ABAQUS. The accuracy and reliability of the subroutine are verified by numerical simulation and experiment. Xue et al. [19] have established the continuous transition model of the welded joint based on the User-Defined Material Mechanical Behavior (UMAT) subroutine in the ABAQUS and found that the stress field at the crack tip of the continuous transition model deflects to the low yield strength zone. However, the writing progress of UMAT subroutines is complicated.

In this research, for further study of the mechanical characteristic at the crack tip of the SA508 Cl.3-Alloy 52M DMWJ, a heterogeneous material model has been established based on the USDFLD subroutine, and it has been compared with the traditional "Sandwich" material model. Furthermore, the stress-strain condition and plastic zone at the crack tips in interface zones are analyzed based on FEM, which provided a new method for accurately analyzing the mechanical field at the crack tip of DMWJs.

\section{Calculation Model}

2.1. Specimen and Material Model. Compact tension (CT) specimens are usually used in the SCC experiments in hightemperature of nuclear power plants materials, and their geometric dimensions are shown in Figure 1 [20]. Due to the limitation in the size of the SA508 Cl.3-Alloy 52M DMWJ, the $0.5 \mathrm{~T}$-CT specimen with prefabricated crack was performed in FEM analysis and guided by the American Society for Testing and Materials Standards [21].

The schematic diagram of the $0.5 \mathrm{~T}-\mathrm{CT}$ specimen in the SA508 Cl.3-Alloy 52M DMWJ is shown in Figure 2, and the length of the prefabricated crack is $2 \mathrm{~mm}$. During the welding progress, the uneven distribution of the microstructure at the interface zones makes the mechanical properties complicated and unevenly distributed [22, 23]. Therefore, the interface regions between materials of the DMWJ are the focus of the SCC. The materials composed of the "Sandwich" material model and heterogeneous material model are shown in Figure 3. In the heterogeneous material model, the weld transition zone consists of HAZ in base metal (SA508), while the high hardness zone consists of DZ in weld metal (Alloy 52M) with widths of $2 \mathrm{~mm}, 0.1 \mathrm{~mm}$, and $1.7 \mathrm{~mm}$, respectively. In this study, the interface crack is located at the interface between materials in the "Sandwich" material model and at the fusion boundary line in the heterogeneous material model. To study the effect of the mechanical field at the noninterface crack caused by the material constraint effect of DMWJs and the noninterface crack position in the "Sandwich" material model, the heterogeneous material model of DMWJs is shown in Figure 3 and summarized in Table 1.

The Ramberg-Osgood equation can be used to express the true stress-strain $(\sigma-\varepsilon)$ relation of the DMWJ [3], which is written as follows:

$$
\frac{\varepsilon}{\varepsilon_{y}}=\frac{\sigma}{\sigma_{y}}+\alpha\left(\frac{\sigma}{\sigma_{y}}\right)^{n},
$$

where $\sigma_{y}$ is the yield strength, $\varepsilon_{y}$ is the yield strain, and $\alpha$ is the Ramberg-Osgood coefficient. The work hardening exponent $n$ of the welded joint can be simply obtained as follows [24]:

$$
n=\frac{1}{\kappa \ln \left(1390 / \sigma_{y}\right)}
$$

where $k=0.163$.

Some scholars have obtained the microhardness distribution of the DMWJ on the surface of SA508 Cl.3-Alloy $52 \mathrm{M}$, which is shown in Figure 4 . The plateau values of the hardness for the base metal and weld metal are 186 and 175, respectively. Peng et al. [25] have summarized the linear relationship between Vickers hardness $\mathrm{HV}_{0.1}$ and yield strength $\sigma_{y}$. The yield strength of the HAZ of DMWJs can be obtained according to the following equation:

$$
\sigma_{y}=3.28 \mathrm{HV}-211 .
$$

Due to the difference between the chemical composition and strength of the DZ and HAZ, the yield strength $\sigma_{y}$ can be obtained by using the following equation proposed by Pargeter [26]:

$$
\sigma_{y}=3.15 \mathrm{HV}-168 \text {. }
$$

Figure 5 shows the yield strength $\sigma_{y}$ distribution near the SA508 Cl.3-Alloy 52M DMWJ fusion line based on (3) and (4). The yield strength $\sigma_{y}$ of the SA508 Cl.3-Alloy $52 \mathrm{M}$ DMWJ at $340^{\circ} \mathrm{C}$ has been used in the finite element simulation and is shown in Figure 6. The yield strength of base metal and weld metal is $420 \mathrm{MPa}$ and $385 \mathrm{MPa}$ in the "Sandwich" material model, respectively. The black lines shown in Figure 6 represent the yield strength distribution of the heterogeneous material model.

2.2. FEM Model. In the SCC experiments, the crack front along the thickness of the specimen of the SA508 Cl.3-Alloy $52 \mathrm{M}$ DMWJ is mainly dominated by plane strain conditions. Therefore, the elastic-plastic finite element analysis is carried out under the condition of plane strain. The global grid for a specimen containing cracks is shown in Figure 7(a), where the $x$-direction is the direction of the crack growth and the $y$-direction is normal to the direction of the crack at the coordinate system. The finite element model has 12,756 nodes of 8 -node biquadratic plane strain quadrilateral (CPE8). The meshes around the crack tip are refined to investigate the mechanical field distribution near the crack 


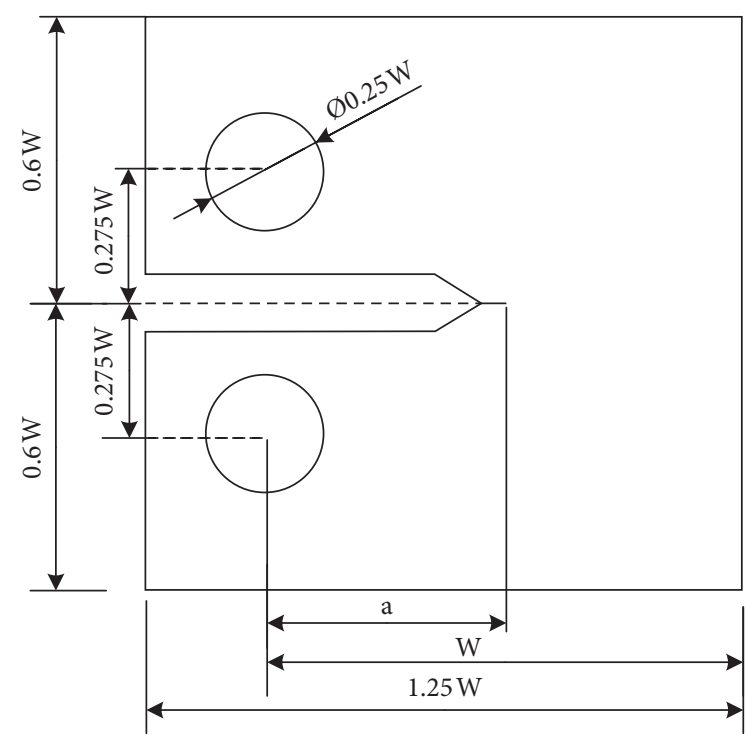

Figure 1: Geometric size of 0.5T-CT specimen (where $W=25 \mathrm{~mm}$ and $a=0.5 \mathrm{~W})$.

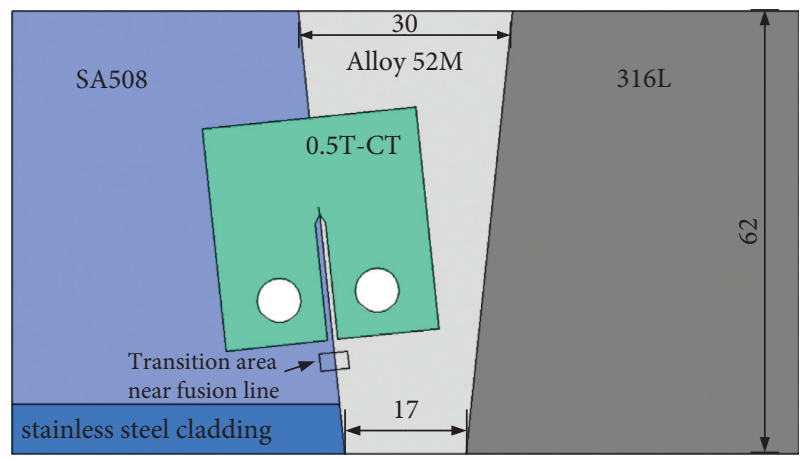

FIGURE 2: Sketch map of sampling in the SA508 Cl.3-Alloy 52M DMWJ.

tip, where 8400 CPE 8 are adopted around the crack tip, as shown in Figure 7(b).

The material constraint effect of DMWJs on the mechanical characteristic at the SCC crack tip has been investigated under the constant load. During the numerical simulation process, the specimen was loaded by concentrated force in the center point of two loaded holes in the vertical direction. All other motions of the center point were restrained except the vertical direction. The coupling constraint was defined between the center point and the loaded hole. The stress intensity factor $\left(K_{I}\right)$ was used as the mechanical parameter, and the constant load was taken as the loading condition of the finite element. In this research, the stress intensity factor was set to be a constant value of $30 \mathrm{MPa} \cdot \mathrm{m}^{1 / 2}$, and the load $P$ can be obtained by

$$
K_{I}=\frac{P}{B \sqrt{W}} f\left(\frac{a}{W}\right)
$$

where $P$ is load and $B$ is sample thickness. As shown in Figure 1 , if $a / W=0.5$, then the $f(a / w)=9.66$.

Three observation paths were established in the finite element model to characterize the influence of the heterogeneous material mechanical properties on the mechanical characteristic around the crack tip in detail. Path 1 and path 2 were established along $45^{\circ}$ and $-45^{\circ}$ in the $\Phi=0.02 \mathrm{~mm}$ circular region around the crack tip, and path 3 was established along the front of the crack tip. Zhang et al. [27] proposed that the region of strain field is $1<r /\left(J / \sigma_{y}\right)<5$, where $J$ is $J$-integral. According to the obtained $J$-integral of the specimen, the distance from the start point to the end point of each path from the crack tip is $0.008 \sim 0.02 \mathrm{~mm}$ in this study, which is shown in Figure 8 .

\subsection{Establishment of Heterogeneous Material Model Based on} USDFLD. There are a lot of material constitutive models provided in the ABAQUS for the users. However, the mechanical properties at the DMWJs are heterogeneous. In this research, a heterogeneous material model of the SA508 Cl.3Alloy 52M DMWJ has been established based on the USDFLD subroutine. The subroutine is used to redefine the field variables at the element integration point, which is programmed in the FORTRAN language [28]. The flowchart of the USDFLD subroutine is shown in Figure 9.

The change of material mechanical properties associated with the functional relationship between longitudinal coordinate $U y$ and the field variable $f x$ in FEM is established. At the same, the predefined material "MAT" in the FEM is invoked by the state variable STATE V $(x)$ for the field variable $f x$. The yield strength $\sigma_{y}$ distribution is fitted according to Figure 6 . The relationship between the field edited function $f x$ and the $y$-direction of the CT specimen is established in the following equation:

$$
f(x)= \begin{cases}420, & y \in[0,12.93), \\ 25.05 * \sin (y-\pi)+3.72\left((y-10)^{2}\right)+396.9, & y \in[12.93,14.93), \\ 40110 *\left((\sin (y-0.8733))^{2}\right)-2638 * y, & y \in[14.93,15.03), \\ -7.991 * y^{3}+414.6 *(y-10)^{2}+1137 * y, & y \in[15.03,16.73), \\ 385, & y \in[16.73,30] .\end{cases}
$$



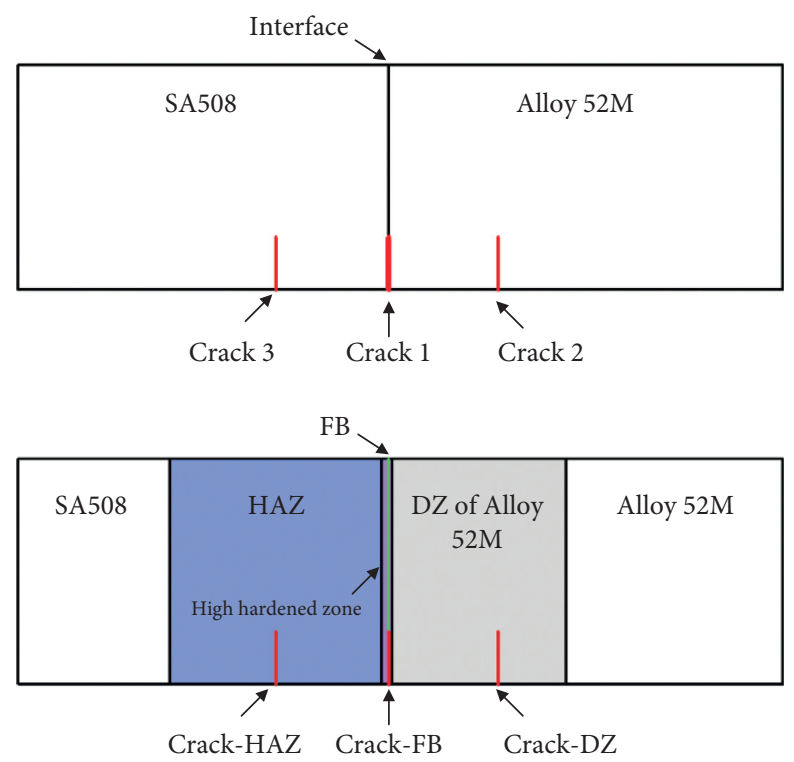

Figure 3: Sketch map of material components crack location of two material models.

TABle 1: A summary of the seven cracks and their locations.

\begin{tabular}{|c|c|c|}
\hline Material model & Crack number & Crack location \\
\hline "Sandwich" material model & $\begin{array}{l}\text { Crack } 1 \\
\text { Crack } 2 \\
\text { Crack } 3\end{array}$ & $\begin{array}{c}\text { SA 508L/Alloy 52M interface } \\
\text { Crack in alloy 52M, distance from crack } 10.5 \mathrm{~mm} \\
\text { Crack in SA 508, distance from crack } 10.5 \mathrm{~mm}\end{array}$ \\
\hline Heterogeneous material model & $\begin{array}{l}\text { Crack-FB } \\
\text { Crack-DZ } \\
\text { Crack-HAZ }\end{array}$ & $\begin{array}{l}\text { Crack in the fusion boundary line } \\
\text { Crack in the DZ, distance from crack-FB } 0.5 \mathrm{~mm} \\
\text { Crack in the HAZ, distance from crack-FB } 0.5 \mathrm{~mm}\end{array}$ \\
\hline
\end{tabular}

\section{Results and Discussions}

3.1. The Stress Field Feature around the Crack Tip. The stress and strain conditions at the crack tip of DMWJs can significantly affect the SCC behavior. They are usually used as mechanical parameters to predict the SCC crack initiation. Figure 10(a) shows the Mises stress $\sigma_{m}$ contour of crack 1 in the range of crack tip at $\Phi=0.8 \mathrm{~mm}$, where the Mises stress contour around crack 1 is suddenly interrupted at the interface between the base metal and weld metal. Therefore, the abrupt change of material mechanical properties at the interface in the "Sandwich" material model will cause discontinuity of the stress filed around the crack tip. The Mises stress $\sigma_{m}$ contour of crack-FB is shown in Figure 10(b). As can be seen from Figure 10(b), the Mises stress contour around the crack tip is continuously distributed in the heterogeneous material model, and the contour near the high hardness zones becomes wrinkled and deformed.

The Mises stress curves along path 1 and path 2 of crack 1 and crack-FB are shown in Figure 11(a), where the Mises stress value near $r=0$ is the largest, and the Mises stress curve value of crack-FB is greater than that of crack 1. Combined with the asymmetric Mises stress contour around the crack tip of crack 1 and crack-FB, the stress curve is symmetrically distributed along the front of the crack in a small region around the crack tip. As shown in
Figure 6, the yield strength of the heterogeneous material model at the fusion line is significantly higher than that at the interface of the "Sandwich" material model. Therefore, the Mises stress value at the interface obtained by the traditional "Sandwich" material model is small. Figure 11(b) shows the Mises stress curves of crack 1, crack 2, and crack 3 in the "Sandwich" model, in which it can be seen that the three curves are varied closely from one another. Therefore, the material constraint effect caused by the material properties of the base metal and weld metal given to the "Sandwich" material model has a little effect on the Mises stress value around crack tip in interface zones.

The Mises stress curves at the crack tip in the heterogeneous material model are shown in Figure 12(a), where the Mises stress curve value at the crack tip is larger than other curves. It is indicated that under the same external load, the Mises stress distribution around the crack tip in the fusion line is larger than that in DZ and $\mathrm{HAZ}$ due to the material constraint effect caused by the welding. Figure 12(b) shows the tensile stress curve ahead of the crack tip along path 3 in the heterogeneous material model, where the tensile stress on the crack tip of crack$\mathrm{FB}$ is the largest. At the same time, the tensile stress around the crack tip of crack-DZ is less than that of the crack-HAZ due to the heterogeneous mechanical 


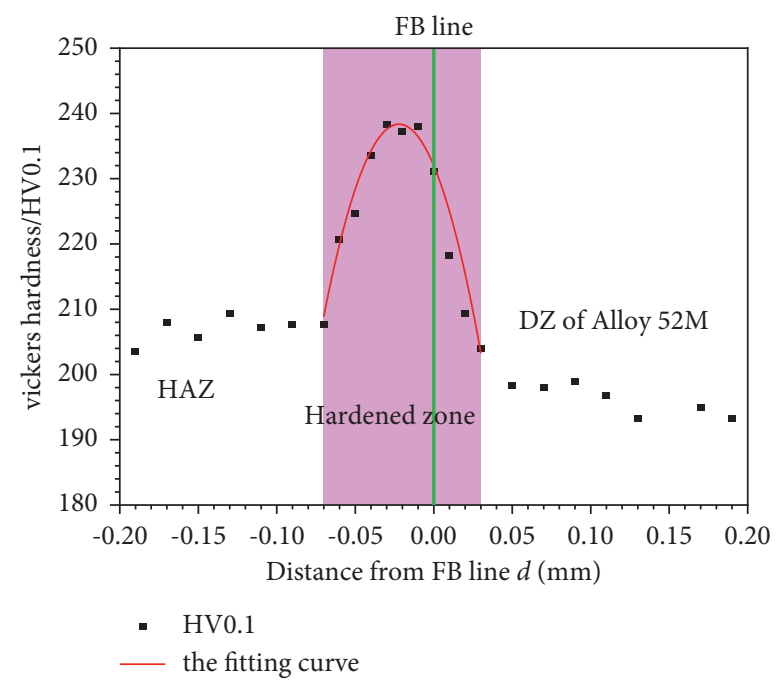

Figure 4: Profile of microhardness in high hardness zone [13, 25].

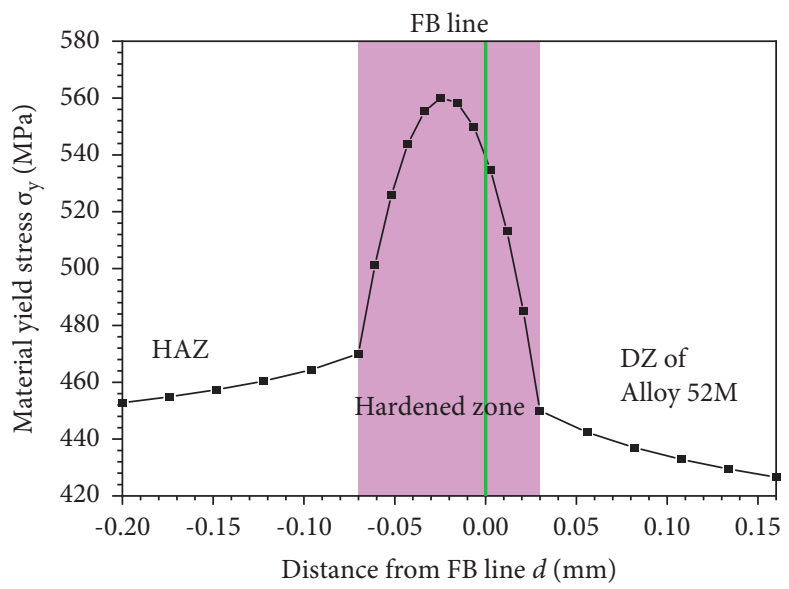

FIGURE 5: Yield stress $\sigma_{y}$ distribution near FB line.

properties of the SA508 Cl.3-Alloy 52M DMWJ. It is indicated that larger tensile stress will be provided for the I-type crack when it is located at the FB line.

3.2. The Strain Field Feature around the Crack Tip. Figure 13 shows the equivalent plastic strain contour around the crack tip in the range of crack tip at $\Phi=0.8 \mathrm{~mm}$. Similar to Mises stress contour around the crack tip in the "Sandwich" material model, the discontinuity of equivalent plastic strain around the crack tip is suddenly interrupted when the crack is present at the interface between the materials, as shown in Figure 13(a). The equivalent plastic strain of crack-FB is shown in Figure 13(b). Contrary to the Mises stress contour around the crack tip in the heterogeneous material model, the equivalent plastic strain around the crack tip is contracted, and it is continuously distributed. This indicates that the yield strength of the crack tip is smaller than that of the base metal and weld metal, and the equivalent plastic strain of the crack tip shrinks. Combined with Figures 10(b) and 11(b), the continuous deformation distribution of Mises stress and equivalent plastic strain contour can verify the yield strength distribution in the SA508 Cl.3-Alloy 52M DMWJ. As shown in Figure 6, the yield strength increases in the high hardness zone, and the corresponding equivalent plastic strain decreases, while the stress value increases.

The equivalent plastic strain $\varepsilon_{e q}$ curves around the crack tip of crack 1 and crack-FB are shown in Figure 14(a). It can be seen that the equivalent plastic strain curves are asymmetrically distributed along with them ahead of the crack tip. Contrary to the Mises stress curve around the crack tip, the equivalent plastic strain curve of crack-FB is smaller than crack 1 . The equivalent plastic distribution curves around crack tip in the "Sandwich" material model are shown in Figure 14(b). It is obvious from Figure 14(b) that the equivalent plastic strain curves around the crack tip of crack 1 , crack 2 , and crack 3 are very close to each other; also, the curves of crack 2 and crack 3 are asymmetrically distributed along with them ahead of the crack tip. But the curve of an 


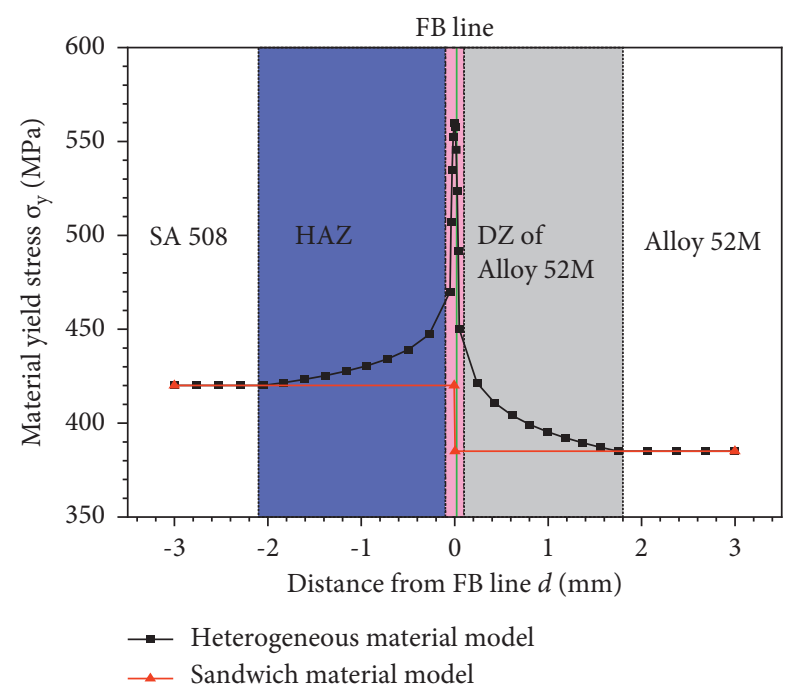

FIGURE 6: Yield stress $\sigma_{y}$ distribution in the transition zone.

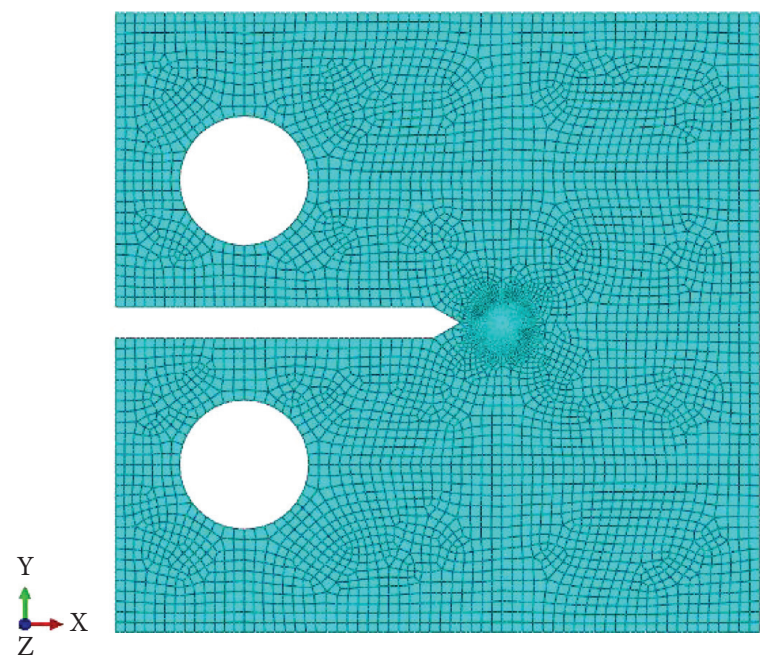

(a)

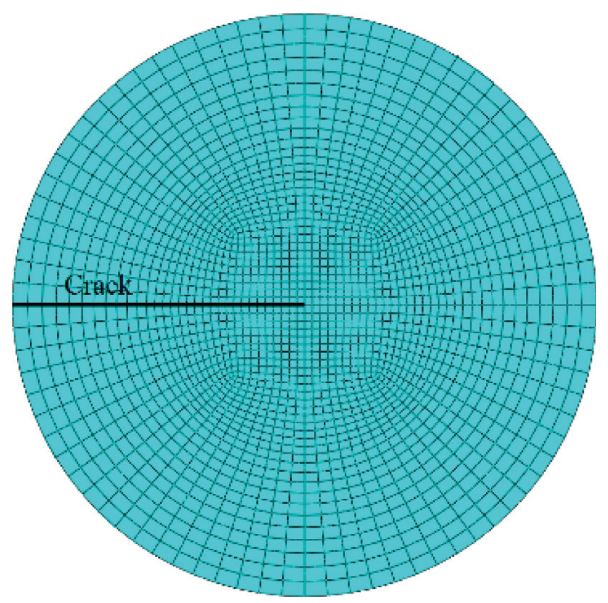

(b)

FIgURE 7: Finite element mesh of 1T-CT specimen. (a) Mesh of the global model and (b) mesh of the crack tip.

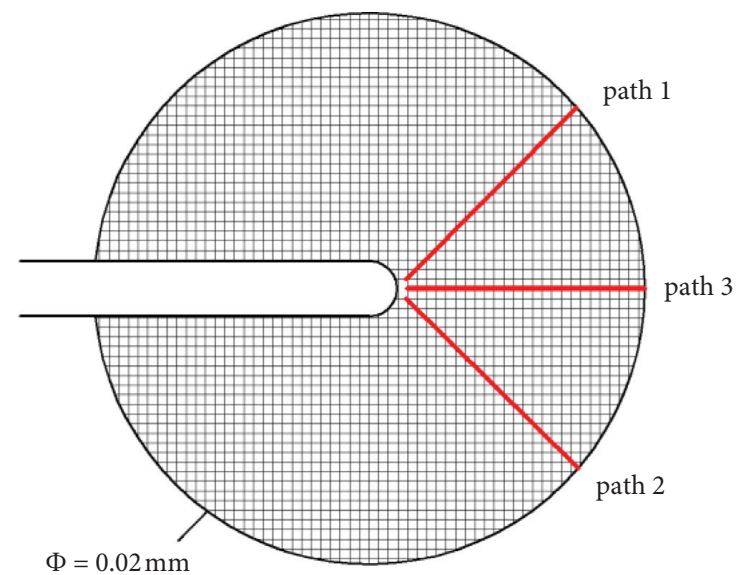

Figure 8: The observation paths around the crack tip. 


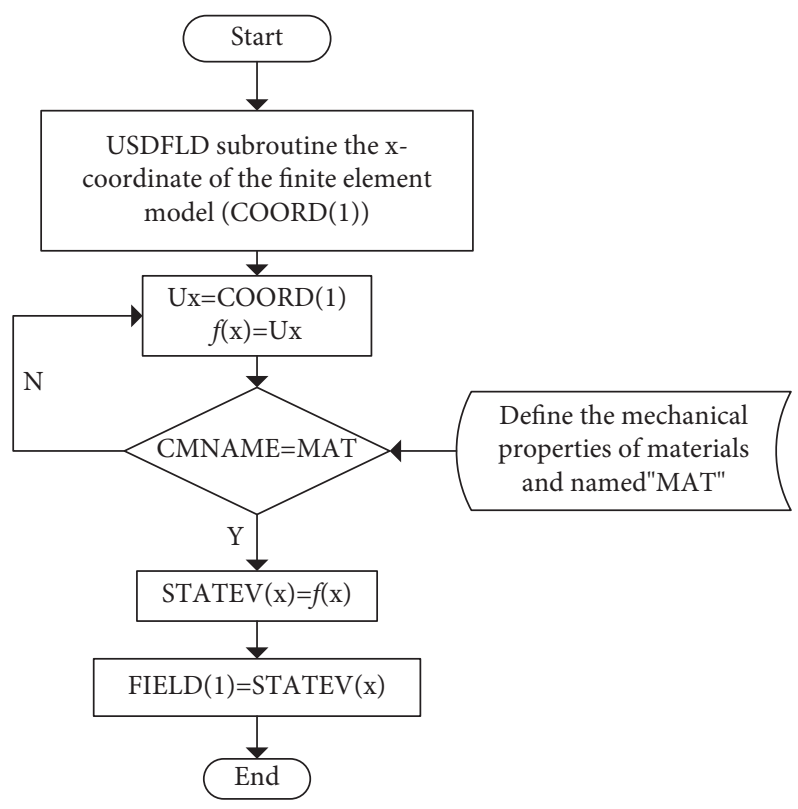

FIGURE 9: The flowchart of USDFLD subroutine.

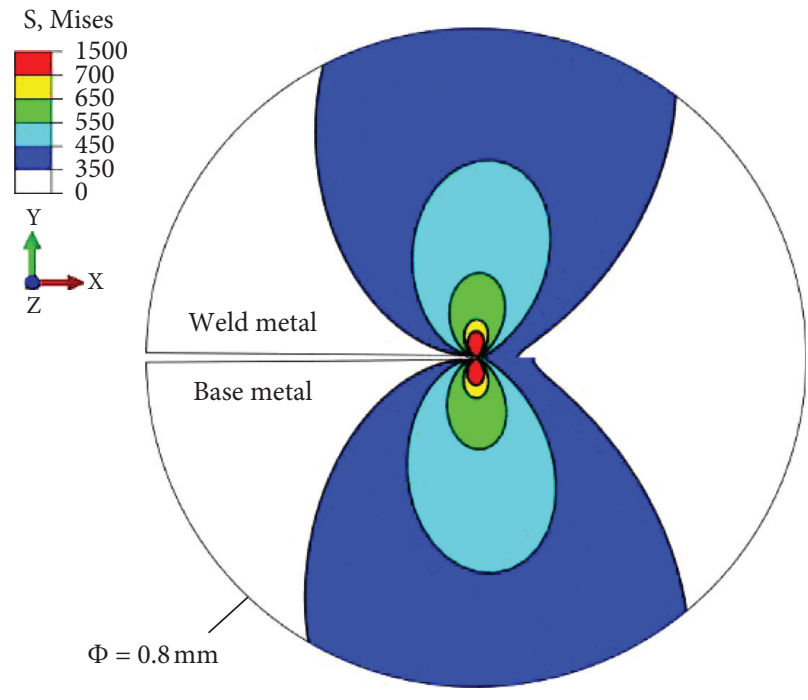

(a)

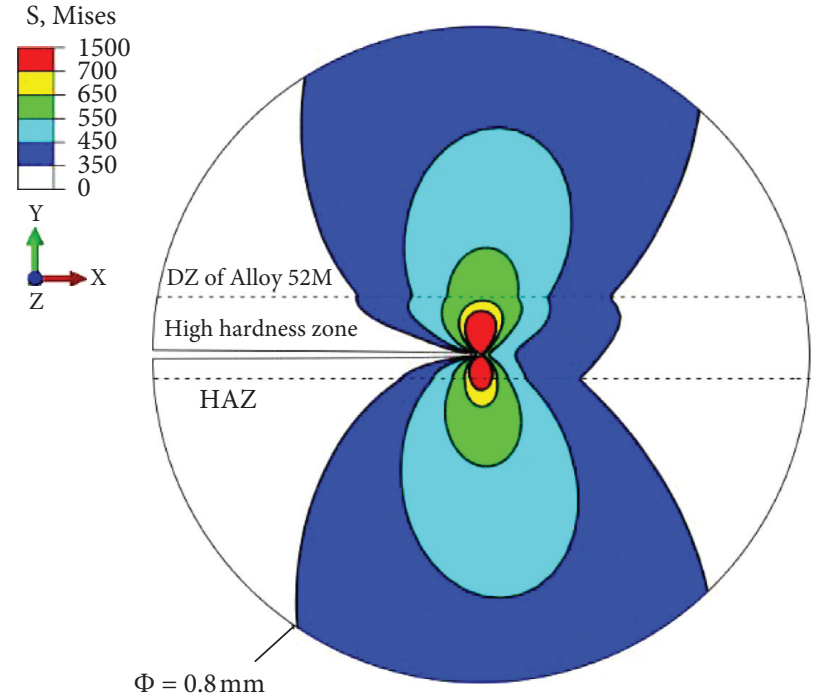

(b)

Figure 10: The Mises stress $\sigma_{m}$ contour around the crack tip. (a) Crack 1 and (b) crack-FB.

interface crack between materials is symmetrical. Therefore, the complex strain field will be generated on both sides of the interface crack caused by the material constraint effect in the "Sandwich" material model.

The equivalent plastic curves at the crack tip in the heterogeneous material model are shown in Figure 15(a). It is evident that the equivalent plastic curve value of crack-FB is smaller than crack-DZ and crack-HAZ, and the curves of
crack-DZ and crack-HAZ are very close to each other. Contrary to the stress field at the crack tip in the heterogeneous material model, the strain field at the crack tip at the fusion line is smaller than that in DZ and HAZ. The normal strain curves ahead of the crack tip along path 3 in the heterogeneous material model are shown in Figure 15(b). It is obvious from Figure 15(b) that the tensile strain on the front of the crack-DZ is the largest. This shows that the DZ is 


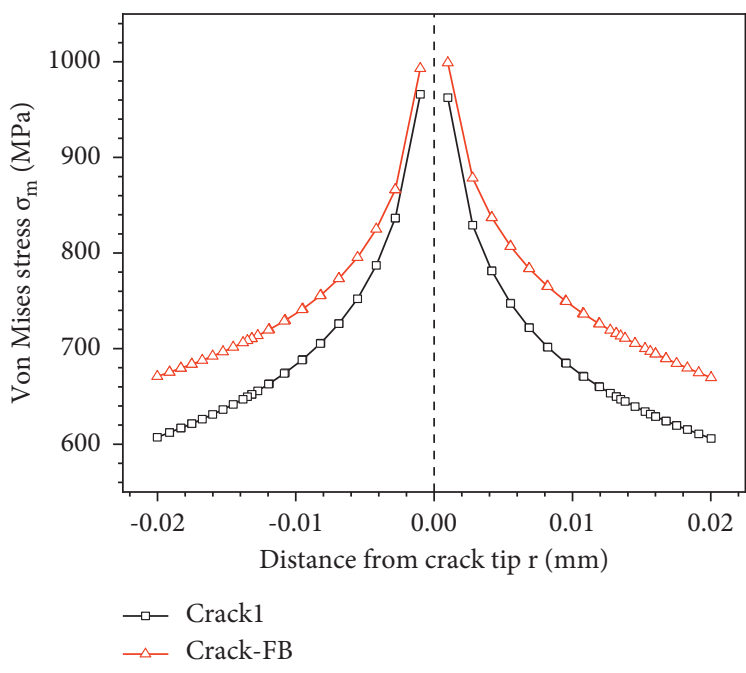

(a)

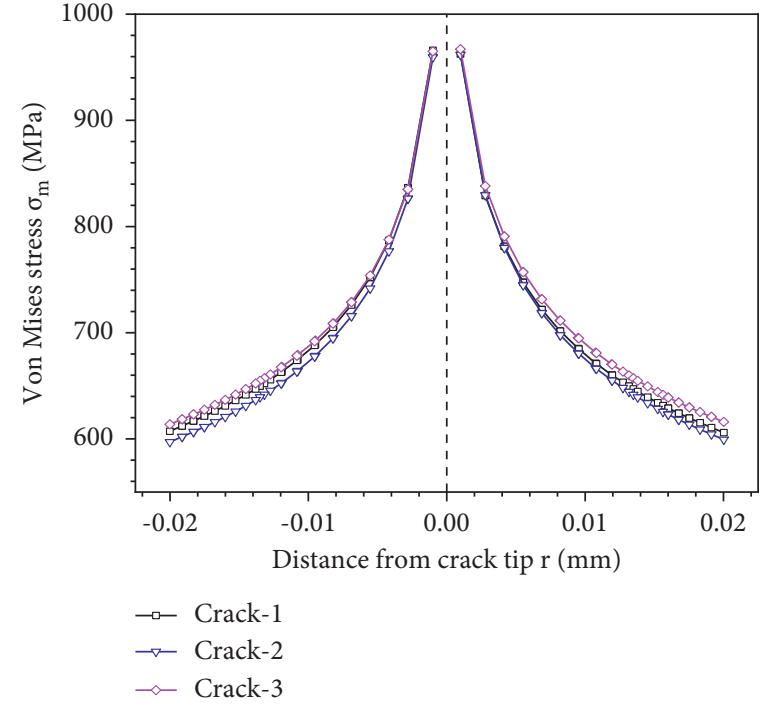

(b)

Figure 11: The Mises stress $\sigma_{m}$ curves at crack tip. (a) Crack 1 and crack-FB and (b) crack 1, crack 2, and crack 3.

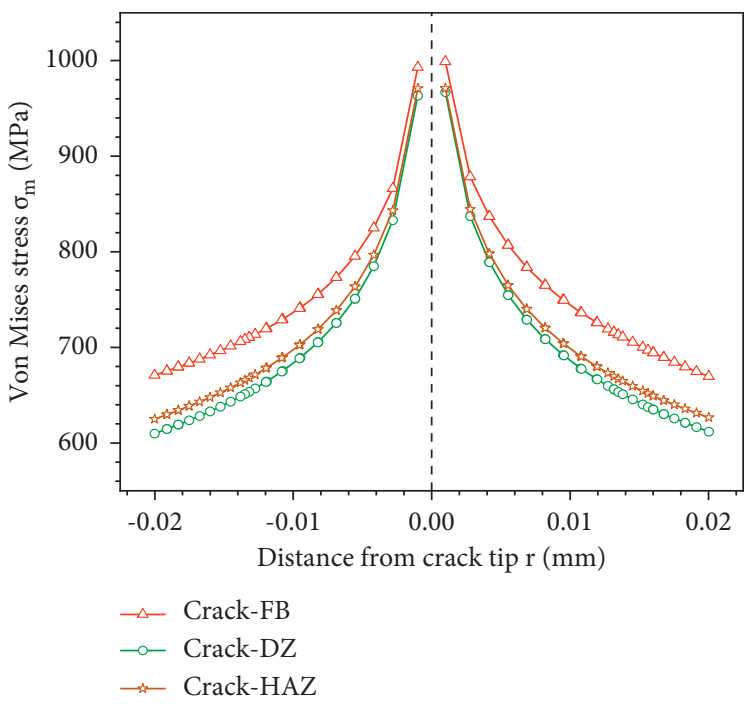

(a)

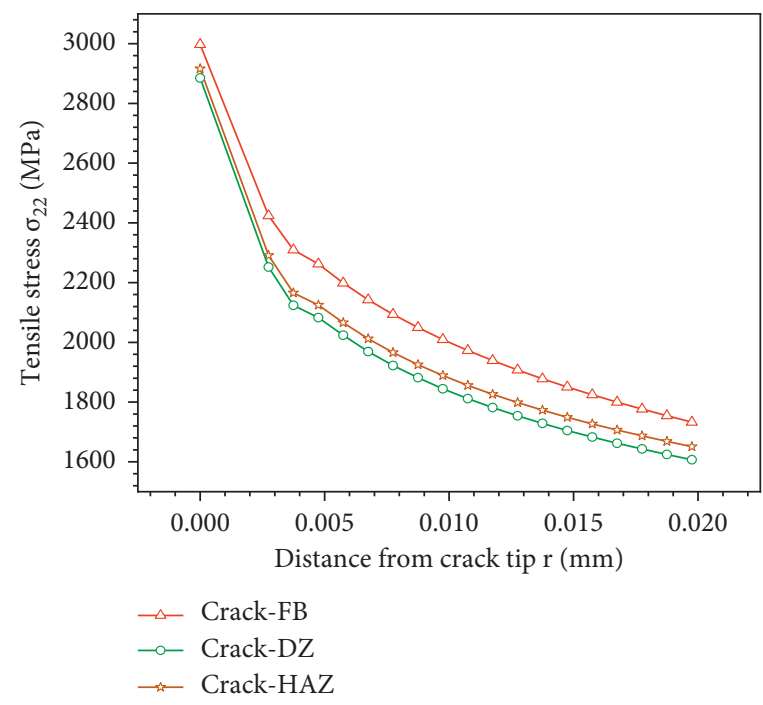

(b)

Figure 12: Stress curves at the crack tip in the heterogeneous material model: (a) von Mises stress $\sigma_{m}$ and (b) tensile stress $\sigma_{22}$.

easily yielded under the same load. From this perspective, the SA508 Cl.3-Alloy 52M dissimilar metal welded joint is more prone to damage in the DZ.

3.3. The Plastic Zone around the Crack Tip. The plastic zone around the crack tip is defined as the yield strain, that is, $0.2 \%$ equivalent plastic strain. The larger plastic zone can store more energy around the crack tip. Therefore, the plastic zone size is an important mechanical parameter for SCC crack initiation. Figure 16(a) shows the distribution of plastic zones at the crack tip at $\Phi=0.8 \mathrm{~mm}$ with interface crack 1 and subinterface crack 2 and crack 3 in the "Sandwich" model, where the plastic zone of crack 1 is asymmetrically distributed along the crack front. The crack tip plastic zone in the weld metal is larger than that of the base metal. The plastic zones of noninterface crack 2 and crack 3 are symmetrically distributed along the crack front. These results indicate that more energy is stored in the plastic zone near the weld metal. From this point of view, interface crack 1 will be deflected from the weld metal. The plastic zones around the crack tip at the transition zone of the heterogeneous material model are shown in Figure 16(b), where the plastic zones of the crack are asymmetrical. Moreover, the plastic zone area at the crack-DZ is larger than crack-FB and crack-HAZ. By 


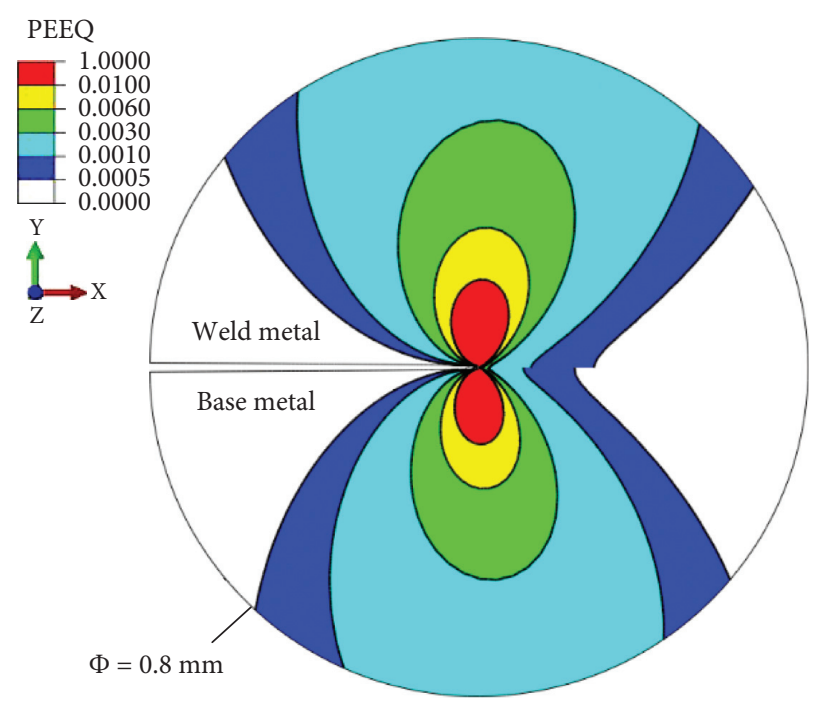

(a)

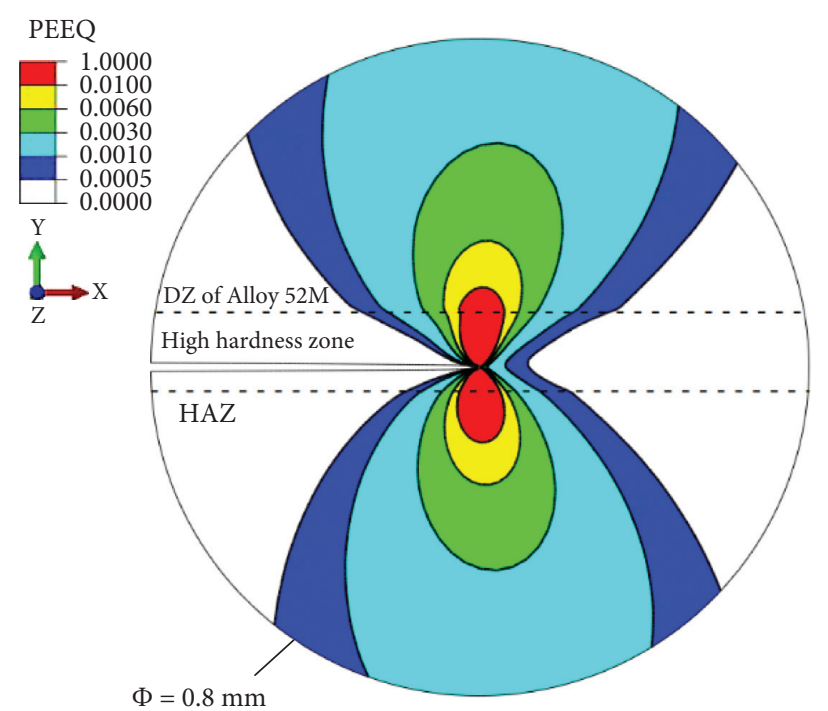

(b)

FiguRe 13: Equivalent plastic strain $\varepsilon_{e q}$ contour distribution at the crack tip. (a) Crack 1 and (b) crack-FB.

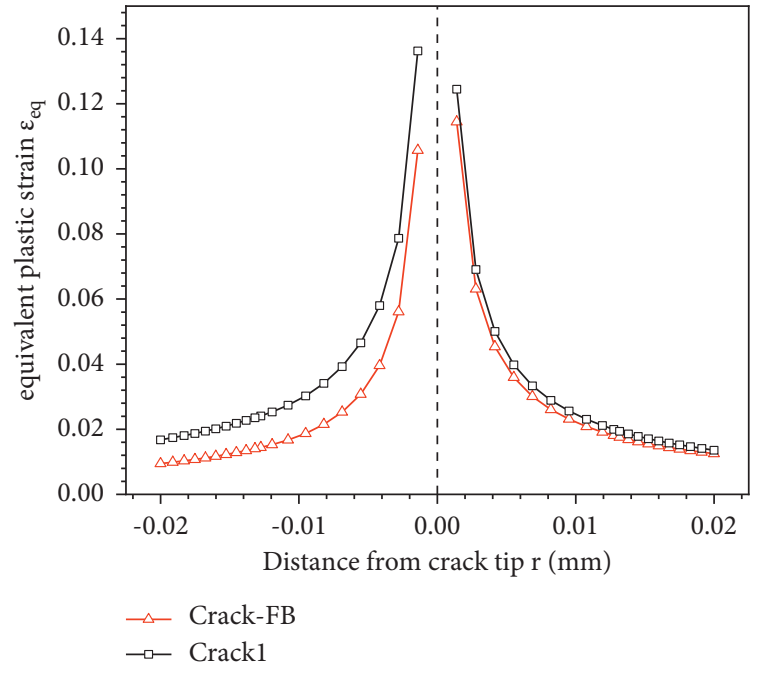

(a)

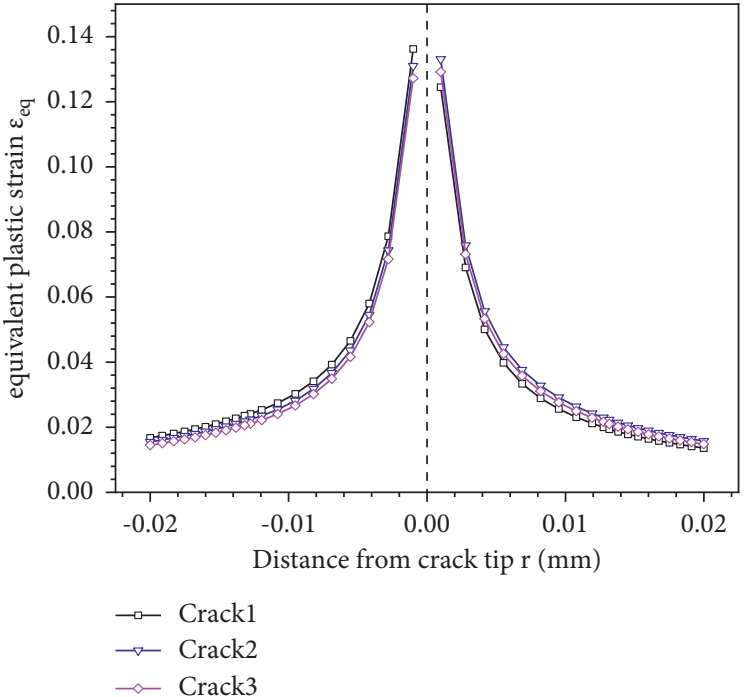

(b)

FIGURE 14: Equivalent plastic strain $\varepsilon_{e q}$ curves of crack tip front. (a) Crack 1 and crack-FB and (b) crack 1, crack 2, and crack 3.

comparing Figures 16(a) and 16(b), the plastic zone around the crack tip of the "Sandwich" material model is larger than the heterogeneous material model. Combined with the yield strength distribution of the heterogeneous material model in Figure 6, it is obvious that the crack tip plastic zone will decrease as the yield strength increases under the same load. Therefore, the plastic zone around the crack tip at the interface zone between materials based on the traditional "Sandwich" material model will be larger. 


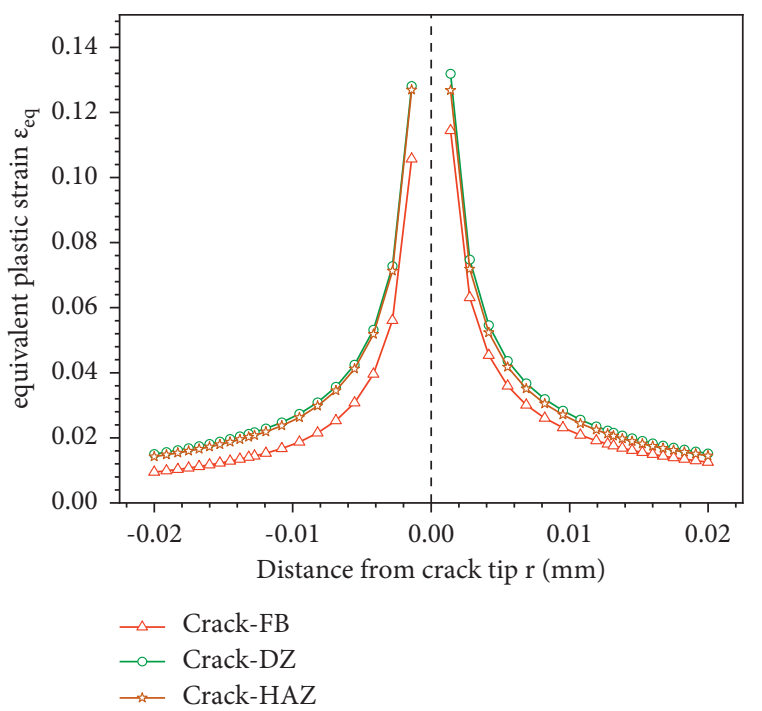

(a)

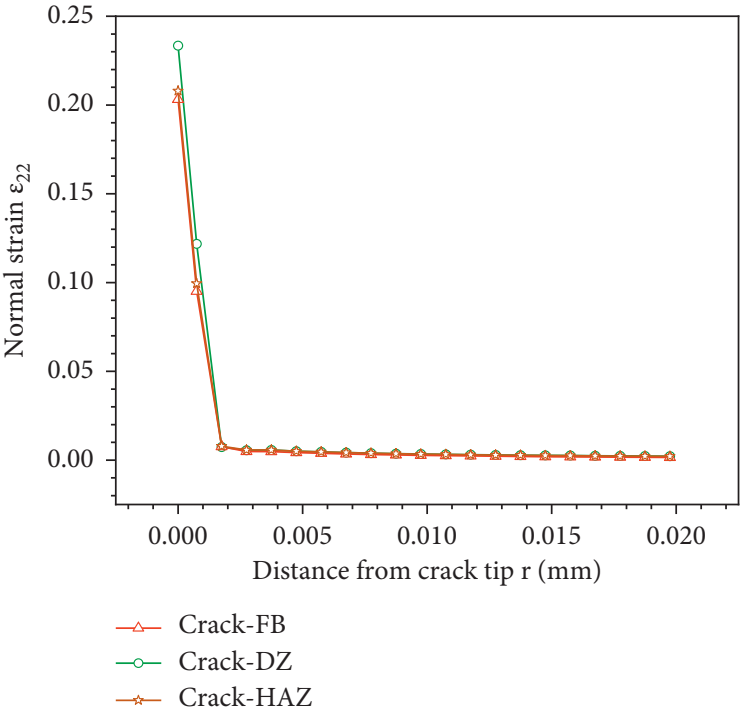

(b)

FIGURE 15: Strain curves of crack tip in heterogeneous material model. (a) Equivalent plastic strain $\varepsilon_{e q}$ and (b) normal strain $\varepsilon_{22}$.

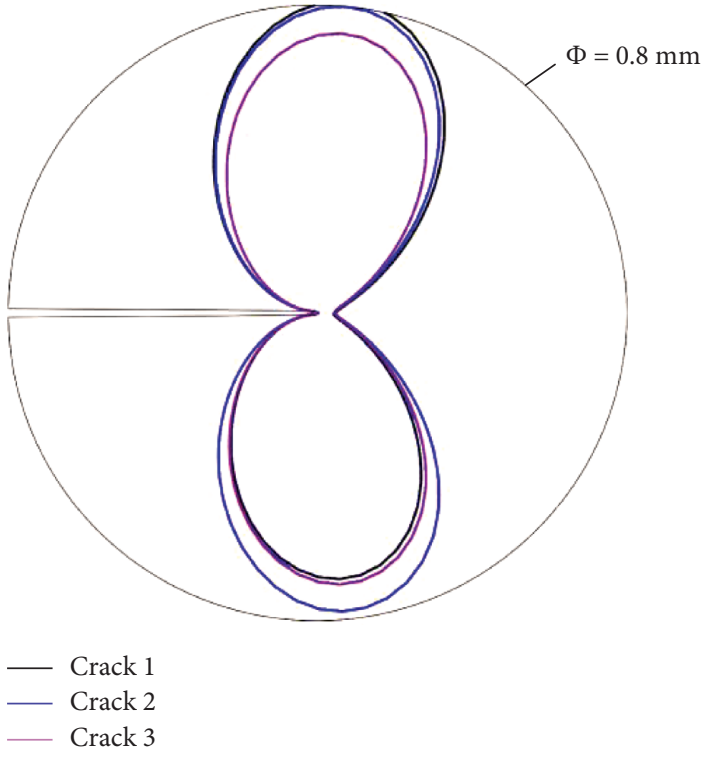

(a)

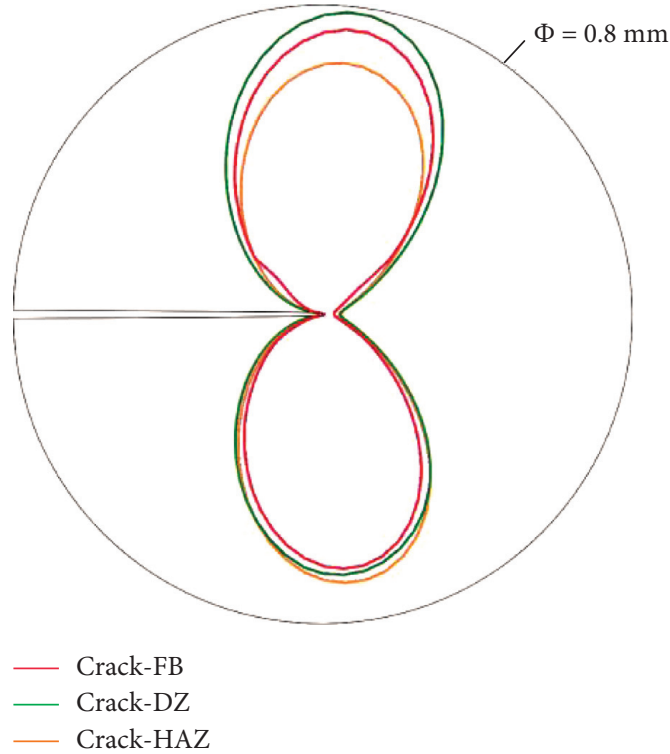

(b)

FIGURE 16: Distribution of plastic zone around the crack tip. (a) "Sandwich" material model and (b) heterogeneous material model.

\section{Conclusions}

In this research, the heterogeneous material model of the SA508 Cl.3-Alloy 52M DMWJ has been established based on the USDFLD subroutine. The comparison of the traditional "Sandwich" model with the heterogeneous material properties, the stress and strain condition, and the plastic zone around the crack tip at interface zones is analyzed by the finite element method. The main acquired results are summarized as follows:

(1) By comparing the stress and strain contour around the crack tip in two material models, it is concluded that the stress and strain contour is symmetrical at the interface zones in the heterogeneous material model based on the USDFLD subroutine, which eliminates the sudden changes of the contour caused by the material properties given by the "Sandwich" material model.

(2) When the stress intensity factor $K_{I}$ is constant, the crack at the fusion line obtains greater tensile stress in the heterogeneous material model, which provides a greater driving force for SCC crack to initiate. However, the variations in the tensile stress around the crack tip difference between 
interface crack and noninterface crack in the "Sandwich" material model can be ignored.

(3) By considering the effect of the plastic zone and the strain curves around the crack tip carefully, it is concluded that both material models show that the crack at the interface zones between materials is more likely to deflect along with the weld metal.

\section{Data Availability}

The article includes the numerical simulation data of the stress and strain curves and the plastic zone around the crack-tip used to support this study's findings.

\section{Conflicts of Interest}

The authors declare that they have no conflicts of interest.

\section{References}

[1] H. Ming, Z. Zhang, J. Wang, E.-H. Han, P. Wang, and Z. Sun, "Microstructure of a safe-end dissimilar metal weld joint (SA508-52-316L) prepared by narrow-gap GTAW," Materials Characterization, vol. 123, pp. 233-243, 2017.

[2] H. P. Seifert, S. Ritter, T. Shoji, Q. J. Peng, Y. Takeda, and Z. P. Lu, "Environmentally-assisted cracking behaviour in the transition region of an alloy 182/SA $508 \mathrm{Cl} .2$ dissimilar metal weld joint in simulated boiling water reactor normal water chemistry environment," Journal of Nuclear Materials, vol. 378, no. 2, pp. 197-210, 2008.

[3] L. Dong, Q. Peng, H. Xue, E.-H. Han, W. Ke, and L. Wang, "Correlation of microstructure and stress corrosion cracking initiation behaviour of the fusion boundary region in a SA508 Cl. 3-alloy 52M dissimilar weld joint in primary pressurized water reactor environment," Corrosion Science, vol. 132, pp. 9-20, 2018.

[4] J. Hou, Q. Peng, Y. Takeda, J. Kuniya, and T. Shoji, "Microstructure and stress corrosion cracking of the fusion boundary region in an alloy 182-A533B low alloy steel dissimilar weld joint," Corrosion Science, vol. 52, no. 12, pp. 3949-3954, 2010.

[5] J. G. Thakare, C. Pandey, A. Gupta, P. K. Taraphdar, and M. M. Mahapatra, "Role of the heterogeneity in microstructure on the mechanical performance of the autogenous gas tungsten arc (GTA) welded dissimilar joint of F/M P91 and SS304L steel," Fusion Engineering and Design, vol. 168, Article ID 112616, 2021.

[6] H. Ming, Z. Zhang, J. Wang, and E.-H. Han, "Microstructure of a domestically fabricated dissimilar metal weld joint (SA508-52M-309L-CF8A) in nuclear power plant," Materials Characterization, vol. 148, pp. 100-115, 2019.

[7] X. Di, D. Geng, S. Wu, D. Wang, Z. Zhang, and C. Li, "Solidification behaviour and microstructure of welding transition zone using low-transformation-temperature welding consumables," Science and Technology of Welding \& Joining, vol. 24, no. 2, pp. 148-155, 2019.

[8] J. P. Oliveira, N. Schell, N. Zhou, L. Wood, and O. Benafan, "Laser welding of precipitation strengthened Ni-rich NiTiHf high temperature shape memory alloys: microstructure and mechanical properties," Materials \& Design, vol. 162, pp. 229-234, 2019.

[9] A. Shamsolhodaei, J. P. Oliveira, N. Schell, E. Maawad, B. Panton, and Y. N. Zhou, "Controlling intermetallic compounds formation during laser welding of NiTi to $316 \mathrm{~L}$ stainless steel," Intermetallics, vol. 116, Article ID 106656, 2020.

[10] G. Dak and C. Pandey, "A critical review on dissimilar welds joint between martensitic and austenitic steel for power plant application," Journal of Manufacturing Processes, vol. 58, pp. 377-406, 2020.

[11] C. Hamilton, M. Kopyściański, A. Węglowska, S. Dymek, and A. Pietras, "A numerical simulation for dissimilar aluminum alloys joined by friction stir welding," Metallurgical and Materials Transactions A, vol. 47, no. 9, pp. 4519-4529, 2016.

[12] H. Xue, K. Ogawa, and T. Shoji, "Effect of welded mechanical heterogeneity on local stress and strain ahead of stationary and growing crack tips," Nuclear Engineering and Design, vol. 239, no. 4, pp. 628-640, 2009.

[13] K. Angamuthu, B. Guha, and D. R. G. Achar, "Investigation of dynamic fracture toughness (JId) behaviour of strength mismatched Q \& T steel weldments using instrumented Charpy impact testing," Engineering Fracture Mechanics, vol. 64, no. 4, pp. 417-432, 2018.

[14] Y.-J. Kim, M. Koçak, R. A. Ainsworth, and U. Zerbst, "SINTAP defect assessment procedure for strength mismatched structures," Engineering Fracture Mechanics, vol. 67, no. 6 , pp. 529-546, 2000.

[15] H. Ming, R. Zhu, Z. Zhang et al., "Microstructure, local mechanical properties and stress corrosion cracking susceptibility of an SA508-52M-316LN safe-end dissimilar metal weld joint by GTAW," Materials Science and Engineering: A, vol. 669, pp. 279-290, 2016.

[16] H. T. Wang, G. Z. Wang, F. Z. Xuan, C. J. Liu, and S. T. Tu, "Local mechanical properties of a dissimilar metal welded joint in nuclear powersystems," Materials Science and Engineering: A, vol. 568, pp. 108-117, 2013.

[17] S. Geng, J. Sun, L. Guo, and H. Wang, "Evolution of microstructure and corrosion behavior in 2205 duplex stainless steel GTA-welding joint," Journal of Manufacturing Processes, vol. 19, pp. 32-37, 2015.

[18] Z. Chi, Z. Meng, L. Xie, W. Wang, and W. Zhang, "A finite element method based on modified Alonso unsaturated soil constitutive model," IOP Conference Series: Earth and Environmental Science, vol. 692, no. 4, Article ID 042034, 2021.

[19] H. Xue, Y. Bi, S. Wang, J. Zhang, and S. Gou, "Compilation and application of UMAT for mechanical properties of heterogeneous metal welded joints in nuclear power materials," Advances in Materials Science and Engineering, vol. 2019, Article ID 3151823, 12 pages, 2019.

[20] R. Zhu, J. Wang, Z. Zhang, and E.-H. Han, "Stress corrosion cracking of fusion boundary for $316 \mathrm{~L} / 52 \mathrm{M}$ dissimilar metal weld joints in borated and lithiated high temperature water," Corrosion Science, vol. 120, pp. 219-230, 2017.

[21] Astm Standard E399-90, "Standard test method for plane strain fracture toughness of metallic materials," in Annual Book of ASTM Standards, American Society for Testing and Materials (ASTM), West Conshohocken, PA, USA, 2002.

[22] W. B. Wang, H. Xue, F. Q. Yang, and X. S. Zhou, "Characteristic of interface crack propagation in dissimilar weld joints," Advanced Materials Research, vol. 988, pp. 249-252, 2014.

[23] Y. Wang, H. Cui, M. Fan, Y. Chen, and F. Lu, "Characterization on the gradient microstructure near the fusion interface of dissimilar metal between high Cr heat-resistant steel and Ni-based Alloy 617," Materials Characterization, vol. 151, pp. 227-236, 2019. 
[24] Q. Peng, H. Xue, J. Hou et al., "Role of water chemistry and microstructure in stress corrosion cracking in the fusion boundary region of an alloy 182-A533B low alloy steel dissimilar weld joint in high temperature water," Corrosion Science, vol. 53, no. 12, pp. 4309-4317, 2011.

[25] Y. Peng, C. Wu, J. Gan, and J. Dong, "Characterization of heterogeneous constitutive relationship of the welded joint based on the stress-hardness relationship using microhardness tests," Construction and Building Materials, vol. 202, pp. 37-45, 2019.

[26] R. J. Pargeter, "Yield strength from hardness: a reappraisal for weld metal," Welding Institute Research Bulletin, vol. 11, pp. 325-326, 1978.

[27] Z. L. Zhang, M. Hauge, and C. Thaulow, "Two-parameter characterization of the near-tip stress fields for a bi-material elastic-plastic interface crack," International Journal of Fracture, vol. 79, no. 1, pp. 65-83, 1996.

[28] Dassault Systèmes Simulia Corp, ABAQUS, Version 6.14 Documentation, Dassault Systèmes Simulia Corp, Providence, RI, USA, 2014. 